\title{
Identification, characterization, and quantitative expression analysis of rainbow trout myostatin-1a and myostatin-1b genes
}

\author{
Dilip K Garikipati ${ }^{1}$, Scott A Gahr ${ }^{2}$ and Buel D Rodgers ${ }^{1,3}$ \\ ${ }^{1}$ School of Molecular Biosciences and ${ }^{2}$ Department of Animal Sciences, Washington State University, 124 ASLB, Pullman, Washington 99164-6351, USA \\ ${ }^{3}$ United States Department of Agriculture, National Center for Cool and Cold Water Aquaculture, Kearneysville, West Virginia 25430, USA \\ (Requests for offprints should be addressed to B D Rodgers; Email: danrodgers@wsu.edu)
}

\begin{abstract}
Myostatin is a potent negative regulator of skeletal muscle growth. Although several cDNA clones have been characterized in different vertebrates, the genomic organization and bioactivity of non-mammalian homologs have not. The intron/exon organization and promoter subsequence analysis of two rainbow trout myostatin genes, $r t M S T N-1 a$ and $r t M S T N-1 b$ (formerly 1 and 2 respectively), as well as a quantitative assessment of their embryonic, larval, and adult tissue expression profiles are reported herein. Each gene was similarly organized into three exons of 490, 368, and $1600 \mathrm{bp}$ for MSTN-1a and 486, 386, and 1419 bp for MSTN-1b. Comparative mapping of coding regions from several vertebrate myostatin genes revealed a common organization between species, including conserved pre-mRNA splice sites; the first among the fishes and the second across all vertebrate species. In silico subsequence analysis of the promoter regions identified E-boxes and other putative myogenic response elements. However, the number and diversity of elements were considerably less than those found in mammalian promoters or in the recently characterized zebrafish
\end{abstract}

$M S T N-2$ gene. A quantitative analysis of the embryonic expression profile for both genes indicates that rtMSTN-1a expression is consistently greater than that of rtMSTN-1b and neither gene is significantly expressed throughout gastrulation. Expression of both steadily increases fourfold during somitogenesis and subsides as this period ends. After eyeing, however, rtMSTN-1a mRNA levels ultimately rise 20-fold by day 49 and peak before hatching and yolk sac absorption (YSA). Levels of rtMSTN-1b rise similarly, but do not peak before YSA. An analysis of adult (2-year-old fish) tissue expression indicates that both transcripts are present in most tissues although levels are highest in brain, testes, eyes, muscle, and surprisingly spleen. These studies suggest that strong selective pressures have preserved the genomic organization of myostatin genes throughout evolution. However, the different expression profiles and putative promoter elements in fishes versus mammals suggests that limitations in myostatin function may have evolved recently.

Journal of Endocrinology (2006) 190, 879-888

\section{Introduction}

Muscle growth results from the proliferation of myoblasts and their subsequent differentiation into muscle fibers. This process is regulated in vivo through mechanisms that involve cell-to-cell interactions, cell-to-matrix interactions, and extracellular secreted factors including myostatin (also known as growth/differentiating factor (GDF)-8) (Lee 2004). This member of the transforming growth factor (TGF) $\beta$-superfamily is a potent negative regulator of skeletal muscle growth. Indeed, a myostatin-null phenotype in domestic mammals is characterized by extreme gains in muscle mass, commonly referred to as 'double muscling' (Kambadur et al. 1997, McPherron \& Lee 1997). In addition, a $5^{\prime}$ splice site mutation in the first intron of the human myostatin gene has recently been reported in a child with extraordinary musculature (Schuelke et al. 2004). Increased muscle growth in all these models results from both muscle cell hyperplasia and hypertrophy as myostatin influences myosatellite cells directly (Thomas et al. 2000, Rios et al. 2001, 2002, Langley et al. 2002, 2004, McCroskery et al. 2003). These results together suggest that the biological functions of myostatin are conserved in all mammals, although they are yet to be described in other vertebrates.

A recent phylogenetic analysis of the entire myostatin/GDF-11 subfamily (Kerr et al. 2005) indicates that bony fish possess multiple myostatin genes and that a gene duplication event during early fish radiation (Amores $e t$ al. 1998, Postlethwait et al. 1998) produced two distinct myostatin clades: MSTN-1 and MSTN-2. A second duplication event within salmonids, likely resulting from tetraploidization, produced two subsequent divisions, one in each clade. This suggests that most, if not all, salmonids possess four distinct myostatin genes: two within the first clade $(1 \mathrm{a}$ and $1 \mathrm{~b})$ and two in the second ( $2 \mathrm{a}$ and $2 \mathrm{~b})$. Both the previously identified rainbow trout cDNA clones, formerly 
named Tmyostatin-1 and Tmyostatin-2, are actually MSTN-1 orthologs. They were, therefore, renamed rtMSTN-1a and rtMSTN-1b respectively, which reflects their true evolutionary relationship to other myostatin genes (Kerr et al. 2005).

Myostatin genes have been characterized in mice (McPherron et al. 1997), humans (Gonzalez-Cadavid et al. 1998), cattle (Jeanplong et al. 2001), and pigs (Stratil \& Kopecny 1999). Although cDNA clones have been characterized in many diverse fish species (Ostbye et al. 2001, Roberts \& Goetz 2001, Rodgers \& Weber 2001, Rodgers et al. 2001, Rescan et al. 2001, Maccatrozzo et al. 2001a, Kocabas et al. 2002, Kerr et al. 2005), very few genes have been completely characterized. This is particularly disconcerting since bony fish, especially teleosts, represent the largest group of extant vertebrates and many of these species are commercially important. Therefore, a better understanding of the genomic sequence and organization of different fish myostatin genes, as well as species-specific expression patterns will significantly interest comparative and agricultural biologists alike. This information will be particularly important in the identification and cloning of $M S T N-2$ genes from different salmonids and will help in distinguishing paralogs from orthologs.

The isolation and characterization of the rtMSTN-1a and $r t M S T N-1 b$ genes, including their respective promoter regions, are reported herein. We additionally report the quantitative assessment of the expression of each gene using detailed RNA panels generated from multiple stages of embryonic/larval development and different adult tissues. These studies indicate strong sequence conservation among all vertebrate myostatin genes. However, the expression patterns and putative promoter elements suggest that the function of myostatin in fish may not be as limited as in mammals.

\section{Materials and Methods}

\section{Isolating genomic myostatin clones}

Genomic DNA was extracted from rainbow trout (Oncorhynchus mykiss) fin clips. Briefly, $3 \mathrm{ml}$ lysis buffer $(30 \mathrm{mM}$ Tris, $8 \mathrm{M}$ urea, $4 \% \mathrm{w} / \mathrm{v}$ Chaps ( $\mathrm{pH} 8 \cdot 0$ ) was added to $50 \mathrm{mg}$ tissue and incubated overnight with proteinase $\mathrm{K}(20 \mathrm{mg} / \mathrm{ml})$ at $60{ }^{\circ} \mathrm{C}$. Three consecutive phenol:chloroform:isoamyl alcohol extractions were then performed and DNA quality was verified on a $1 \%$ agarose gel. Promoter regions were cloned using the Universal Genome walker kit (BD Biosciences, www.bdbiosciences.com) and the manufacturer's protocol. Briefly, genomic DNA was digested with the blunt-end restriction enzymes DraI, EcoRV, PvuII, and StuI, and subsequently ligated to the provided adaptor linkers. Nested PCR with $94^{\circ} \mathrm{C}$ initial denaturation was then performed using gene-specific primers homologous to the known $5^{\prime}$-coding region of each gene (Table 1) and adaptor primers with the Advantage 2 PCR kit (BD Biosciences). The cycle parameters were as follows and used as default unless otherwise specified: an initial denaturation at $94{ }^{\circ} \mathrm{C}$ for $1 \mathrm{~min}$, seven cycles of $94^{\circ} \mathrm{C}$ for $30 \mathrm{~s}$, and $72{ }^{\circ} \mathrm{C}$ for $3 \mathrm{~min}$ followed by 30 cycles of $94^{\circ} \mathrm{C}$ for $30 \mathrm{~s}$, and $67^{\circ} \mathrm{C}$ for $3 \mathrm{~min}$ and a final extension at $67^{\circ} \mathrm{C}$ for $4 \mathrm{~min}$. The PCR products were subcloned into the Topo TA vector (Invitrogen, www. invitrogen.com) and sequenced in the university's genomic core facility. Putative-regulatory elements were identified by subsequence analysis using Matinspector software (Genomatrix, Inc., www.genomatix.de), which searches consensus sequences of known cis-regulatory sequences. The intron sequences were obtained by nested PCR using gene-specific primers for rtMSTN-1a or rtMSTN-1b coding regions and adaptor primers (Table 1) as follows: initial denaturation at $94{ }^{\circ} \mathrm{C}$ for $1 \mathrm{~min}$ followed by 30 cycles of $94^{\circ} \mathrm{C}$ for $30 \mathrm{~s}, 65^{\circ} \mathrm{C}$ for $30 \mathrm{~s}, 72{ }^{\circ} \mathrm{C}$ for $3 \mathrm{~min}$, and a final extension at $72{ }^{\circ} \mathrm{C}$ for $3 \mathrm{~min}$. The resulting amplicons were then cloned as described and sequenced. Flanking primers, specific to each myostatin gene, were then used to amplify and clone the complete genes using Pfu polymerase (Stratagene, www.stratagene.com) and the pCR4-blunt Topo vector (Invitrogen). Intron/exon boundaries were determined by aligning the cDNA sequences to their respective gDNA sequences using ALIGN X (VectorNTI, www.invitrogen.com).

The $3^{\prime}$ untranslated regions were isolated using a $3^{\prime}$ RACE (rapid amplification of cDNA ends) kit (Invitrogen, www. invitrogen.com). The total RNA from juvenile skeletal

Table 1 Primer sequences and annealing temperatures $\left({ }^{\circ} \mathrm{C}\right)$

Sequence $\left(5^{\prime}-3^{\prime}\right)$

\section{Primer name}

MSTN-1a F

MSTN-1a R

MSTN-1b F

MSTN-1b R

$18 \mathrm{~s} F$

$18 \mathrm{~s} R$

$3^{\prime}$ UTR $1 \mathrm{~b} / 1$

$3^{\prime}$ UTR $1 \mathrm{a} / 1$

3'UTR 2

Adaptor primer 1

Adaptor primer 2

$\begin{array}{ll}\text { CTT CAC ATA TGC CAA TAC ATA TTA } & 60 \\ \text { GCA ACC ATG AAA CTG AGA TAA A } & 60 \\ \text { TTC ACG CAA ATA CGT ATT CAC } & 60 \\ \text { GAT AAA TTA GAA CCT GCA TCA GAT TC } & 60 \\ \text { TGC GGC TTA ATT TGA CTC AAC A } & 60 \\ \text { CAA CTA AGA ACG GCC ATG CA } & 60 \\ \text { AAC TCT GTA GTC CGC CTT CAC GCA } & 65 \\ \text { AAC TCT GTA GTC CGC CTT CAC ATA } & 65 \\ \text { CAC CTG CAG AAG TAC CCC CAC ACC } & 65 \\ \text { GTA CTA CGA CTC ACT ATA GGG C } & 67 \\ \text { ACT ATA GGG CAC GCG TGG T } & 67\end{array}$

Anealing temperatures

60

60

60

65

65

67

67 
muscle was extracted using Trizol and reverse transcribed using Superscript reverse transcriptase, according to the manufacturer's protocols (Invitrogen). cDNA was then amplified by PCR using gene-specific forward primers $\left(3^{\prime} \mathrm{UTR} 1 \mathrm{a} / 1\right.$ and $3^{\prime} \mathrm{UTR} 1 \mathrm{~b} / 1$, Table 1$)$ and universal adaptor primers (UAP) provided in the kit. The PCR conditions were as follows: an initial denaturation at $94{ }^{\circ} \mathrm{C}$ for $1 \mathrm{~min}$ followed by 30 cycles of $94^{\circ} \mathrm{C}$ for $30 \mathrm{~s}, 65^{\circ} \mathrm{C}$ for $30 \mathrm{~s}, 72^{\circ} \mathrm{C}$ for $2 \mathrm{~min}$, and a final extension at $72{ }^{\circ} \mathrm{C}$ for $2 \mathrm{~min}$. Nested PCR was subsequently performed with the $3^{\prime} \mathrm{UTR} 2$ forward primer and the abridged universal adaptor primer (AUAP) provided in the kit. The resulting amplicons were subcloned and sequenced as described.

\section{Embryonic and tissue collections}

Rainbow trout were reared at the National Center for Cool and Cold Water Aquaculture, Kearneysville, WV, USA, according to the guidelines approved by the institutional animal care and use committee. An RNA panel was generated from 5000 pooled eggs from multiple females (Trout lodge, October 2004) that were fertilized by milt from two males. Following fertilization, eggs were incubated at approximately $13{ }^{\circ} \mathrm{C}$ throughout embryonic development. In addition to the unfertilized eggs (day 0), developing embryos were collected as whole egg samples daily for the first 14 days, every other day until hatch (day 24), and every third day, thereafter. Each sample contained 18 eggs or embryos or 9 post-hatched larvae that were pooled and several samples were collected at each time-point. Tissues were also removed from 2 -year-old adult fish weighing approximately $2 \mathrm{~kg}$. All samples were flashfrozen in liquid nitrogen and stored at $-80{ }^{\circ} \mathrm{C}$ until RNA isolation. Samples were first powdered using a liquid nitrogen-cooled Bessman Tissue Pulverizer (Spectrum Laboratories, www.spectropor.com) and total RNA was extracted using TRI-reagent with the high-salt solution modification to remove excess glycosylated proteins. The RNA was reconstituted in 20-50 $\mu$ l nuclease-free water and treated with DNase (DNAse RQ-1; Promega, www. promega.com) to remove contaminating genomic DNA. Samples were then re-extracted with TRI-reagent and RNA quality was assessed by agarose gel electrophoresis.

\section{$R N A$ quantification using 'real-time' reverse transcriptase (RT)-PCR}

The total RNA $(2 \mu \mathrm{g})$ was reverse transcribed with $1 \mu \mathrm{g}$ random primers (Promega) and $200 \mathrm{U}$ Moloney Murine Leukemia Virus Reverse Transcriptase (MMLV-RT, Promega) in $40 \mu \mathrm{l}$. Subsequent real-time RT-PCR assays were conducted using the ABI Prism 7900HT Sequence Detection System (www.appliedbiosystems.com) and genespecific primers (MSTN-1a F, MSTN-1a R, MSTN-1b F, and MSTN-1b R, Table 1). For each sample, $1 \mu \mathrm{l}$ cDNA was combined with $7 \cdot 5 \mu$ of $2 \times$ SYBR Green PCR master mix
(Applied Biosystems). For each reaction, $6 \mu \mathrm{l}$ of this mixture was added to $9 \mu \mathrm{l}$ primer mix containing $500 \mathrm{nM}$ of each primer. The reactions were carried out as follows: $50{ }^{\circ} \mathrm{C}$ for $2 \mathrm{~min}, 95^{\circ} \mathrm{C}$ for $10 \mathrm{~min}$, then 40 cycles consisting of $95^{\circ} \mathrm{C}$ for $15 \mathrm{~s}$ and $60^{\circ} \mathrm{C}$ for $1 \mathrm{~min}$. The cycling reaction was followed by a dissociation curve to verify amplification of a single product and amplicons were also verified by DNA sequencing.

The relative standard curve method was employed to quantify gene expression. For each primer set, a serial dilution of a mixed tissue cDNA was used to construct a standard curve for each assay plate. The standard curve was constructed by plotting the threshold cycle $\left(C_{\mathrm{T}}\right)$ versus the natural log of input RNA (ng). This curve was then used to calculate the relative abundance of each transcript in each sample. Myostatin values were then normalized to those of 18 s to control differences in RNA and cDNA loading. Each sample was run in triplicate on a single plate and each plate was run in duplicate. Assays were repeated with different samples and all data are presented as normalized gene expression.

\section{Results}

Genomic organization and comparative mapping of rtMSTN-1a and rtMSTN-1b genes

Complete genomic clones for both $\operatorname{rtMSTN}-1 a$ and $r t M S T N-1 b$ genes were isolated and sequenced (Figs 1 and 2). This includes, approximately, $2 \mathrm{~kb}$ upstream of each initiator. The annotated gene and promoter sequences were then deposited with GenBank and assigned the accession numbers DQ136028 and DQ138300 respectively. Each gene is organized into three exons of similar size with appropriate intron/exon splice sites, a pattern that is conserved with other fish species (Maccatrozzo et al. 2001b, Xu et al. 2003, Kerr et al. 2005) and mammals (McPherron et al. 1997, Gonzalez-Cadavid et al. 1998, Stratil \& Kopecny 1999, Jeanplong et al. 2001). The three rtMSTN-1a exons are 490, 368 , and $1600 \mathrm{bp}$ in size respectively, and are separated by 1072 and $992 \mathrm{bp}$ introns (Fig. 1A). The rtMSTN-1b gene is similarly organized with three exons of 486, 386, and $1419 \mathrm{bp}$ with two, 564 and 778 bp introns intervening (Fig. 2A). The $3^{\prime}$ UTRs were also cloned by $3^{\prime}$ RACE using RNA from adult skeletal muscle and determined to be $1 \cdot 2 \mathrm{~kb}$ in the rtMSTN-1a transcript and $1 \cdot 1 \mathrm{~kb}$ in $\operatorname{rtMSTN}-1 \mathrm{~b}$. This is in contrast with the significantly shorter $3^{\prime}$ UTRs reported previously (Rescan et al. 2001). In addition, two polyadenylation signal sequences (AATAAA) were detected in each $3^{\prime}$ UTR at -17 to $-11 \mathrm{bp}$ and -83 to $-76 \mathrm{bp}$ from the poly A site in rtMSTN-1a and -19 to $-13 \mathrm{bp}$ and -86 to $-80 \mathrm{bp}$ in rtMSTN-1b (Figs 1D and 2D).

The proteolytic processing sites and the entire bioactive domains for both myostatin proteins are entirely encoded within the third exons, which is also true for all previously characterized 
A. Genomic map of rtMSTN-1a

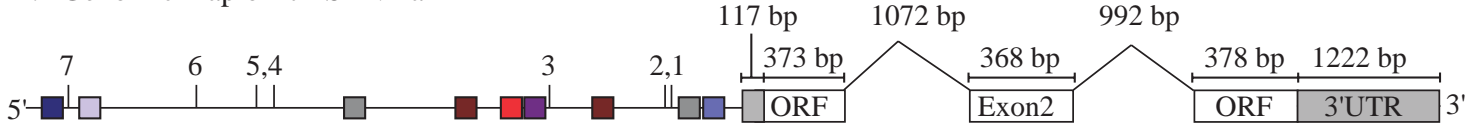

\section{B. rtMSTN-1a promoter}

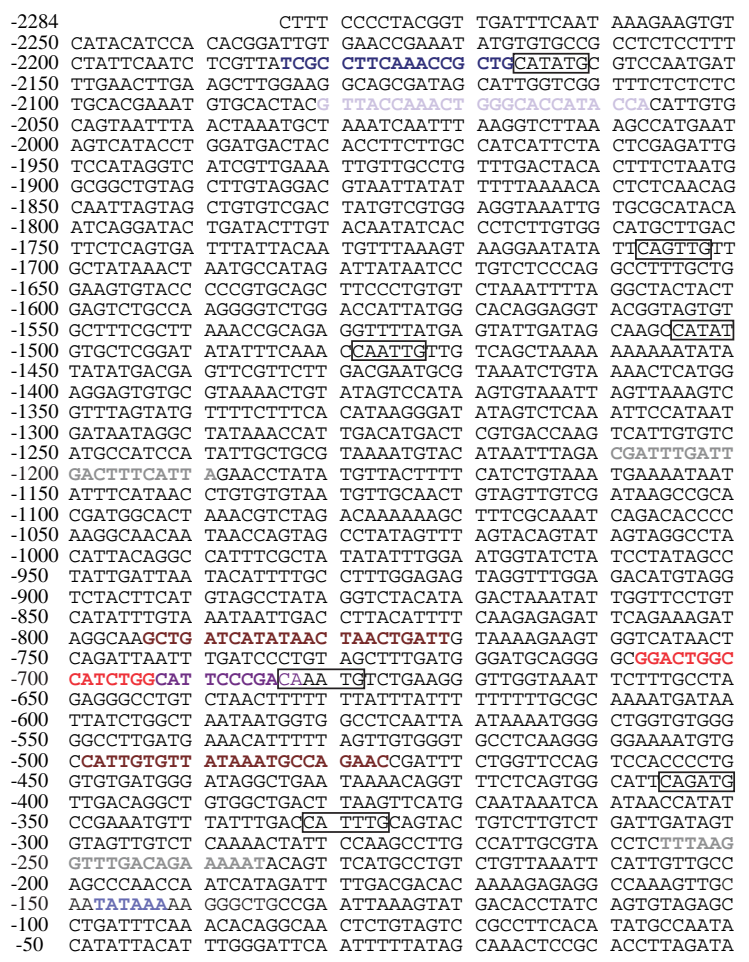

C. Promoter elements of rtMSTN-1a

\begin{tabular}{ll}
\multicolumn{1}{c}{ Name } & Location \\
\hline$\square$ Comp1 & -236 to $-256,-1190$ to -1210 \\
$\square$ HAND2/E12 & -694 to -708 \\
$\square$ MEF2 & -477 to $-499,-772$ to -794 \\
$\square$ MusIn & -2161 to -2184 \\
$\square$ SRF & -2257 to -2281 \\
$\square$ TATAbox & -143 to -147 \\
$\square$ TEF-1 & -683 to -699
\end{tabular}

\section{3'UTR of rtMSTN-1a}

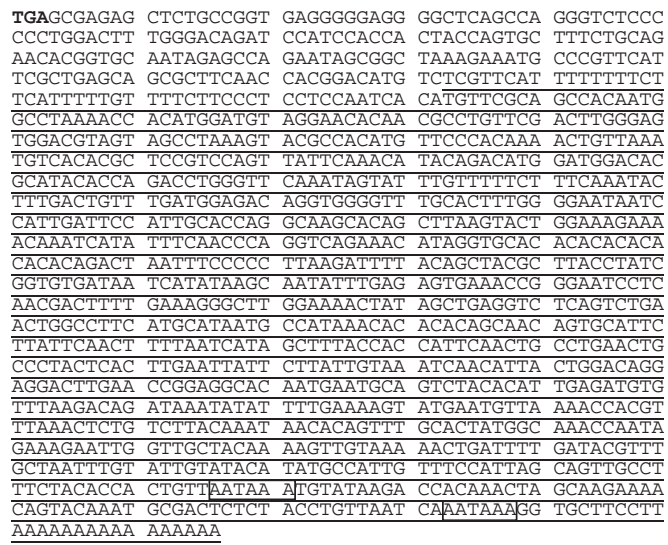

Figure 1 Genomic structure and organization of the rtMSTN-1a gene. (A) Map of rtMSTN-1a gene and putative myogenic cis-regulatory elements within the promoter region. Exons are boxed with the open reading frame (ORF) in white and untranslated regions (UTR) in gray. Each individual cis element is placed relative to its position within the promoter region and color-coded as indicated in C. Putative E-boxes are numbered. (B) Sequence of the promoter region with color-coded cis elements. Boxed are consensus sequences (CAN(T/A)TG) for E-boxes. Nucleotide position corresponds to the initiator. (C) Key to the color-coded-promoter elements in $A$ and $B$, and their corresponding positions. (D) Sequence of the $3^{\prime}$ untranslated region. The newly identified sequence is underlined and two potential polyadenylation signal sequences are boxed.

vertebrate genes (Fig. 3). Comparative mapping of coding regions revealed a common organization between species, including conserved pre-mRNA splice sites. Codons flanking the first splice sites $\left(3^{\prime}\right.$ end of exon 1 and $5^{\prime}$ end of exon 2$)$ are highly conserved among the fishes, while the second site $\left(3^{\prime}\right.$ of exon 2 and $5^{\prime}$ of exon 3 ) is conserved in fish and mammals (Fig. 3). Amino acid consensus sequences were, therefore, identified by comparative sequence analysis of intron/exoncoding junctions. These include $\operatorname{MAT}(\mathrm{E} / \mathrm{K}) \mid \mathrm{PXXI}$ for the first junction and $(\mathrm{G} / \mathrm{E})(\mathrm{E} / \mathrm{D}) \mathrm{GL} \mid \mathrm{XPF} \Phi$ for the second $(\mathrm{X}=$ any amino acid; $\boldsymbol{\Phi}=$ hydrophobic, likely $\mathrm{L}$, I, or $\mathrm{M}$ ). Indeed, multiple sequence alignments with myostatin proteins from different vertebrates, both previously published (Rodgers \& Weber 2001) and repeated with newly discovered clones (data not shown), indicate that these motifs are highly conserved, the first in fishes and the second in all vertebrates.

In silico analysis of $r t M S T N-1 a$ and $r t M S T N-1 b$ promoters

Subsequent analysis of the $2 \mathrm{~kb}$ promoter regions upstream of each gene using MatInspector software identified several putative muscle-specific transcription factor binding sites or cis-regulatory elements. These include Comp1 (cooperates with myogenic proteins 1), HAND2 (heart, autonomic nervous system, neural crest derivative 2), MEF 2 (myocyte enhancer factor 2), MusIn (muscle initiator), SRF (serum response factor), and TEF-1 (transcriptional enhancer factor 1) binding sites in the rtMSTN-1a promoter (Fig. 1). 
A. Genomic map of rtMSTN-1b

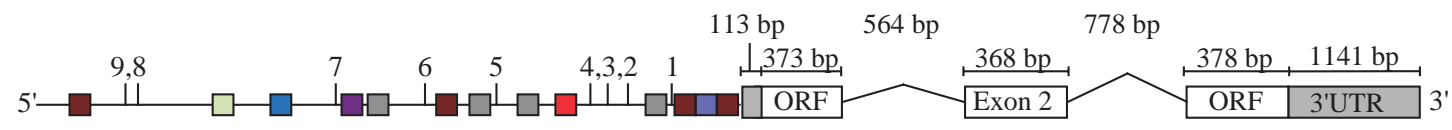

\section{B. rtMSTN-1b promoter}

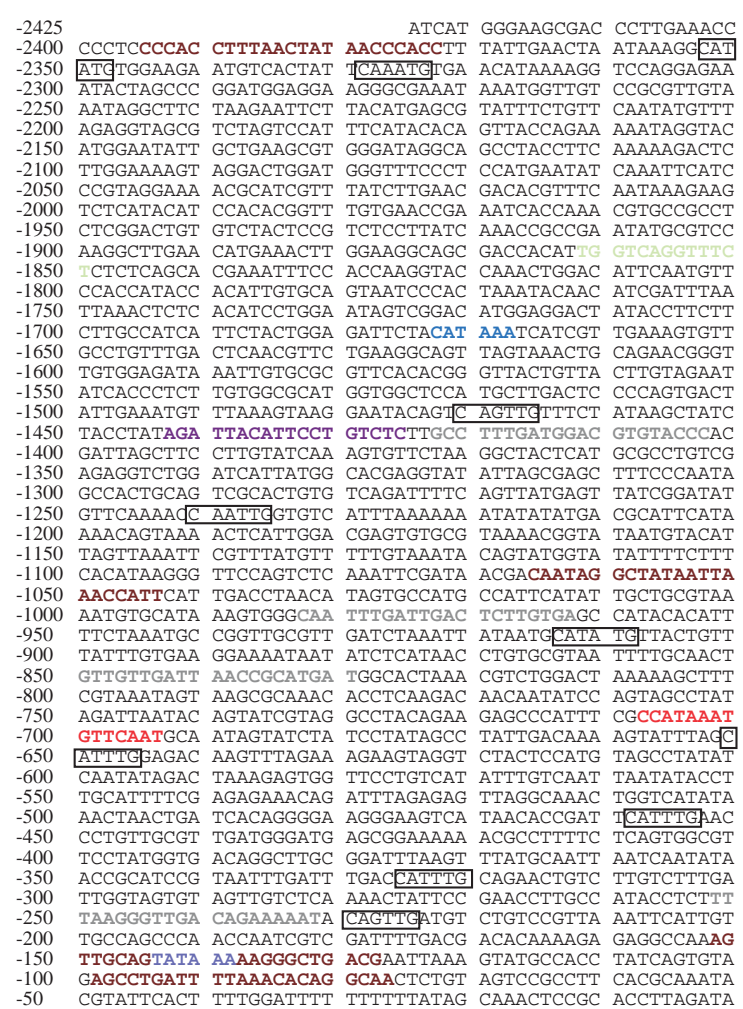

C. Promoter elements of rtMSTN-1b

\begin{tabular}{ll}
\hline$\square$ Comp1 & -232 to $-252,-830$ to -850 \\
& -963 to $-983,-1403$ to -1423 \\
$\square$ Hand2/E12 & -694 to -708 \\
$\square$ MEF2 & -77 to $-99,-128$ to -150 \\
& -1044 to $-1066,-2373$ to -2395 \\
$\square$ MEF3 & -1850 to -1862 \\
$\square$ MuscleTATA & -1660 to -1676 \\
$\square$ TATABox & -139 to -144 \\
$\square$ TEF-1 & -1427 to -1443
\end{tabular}

\section{3'UTR of rtMSTN-1b}

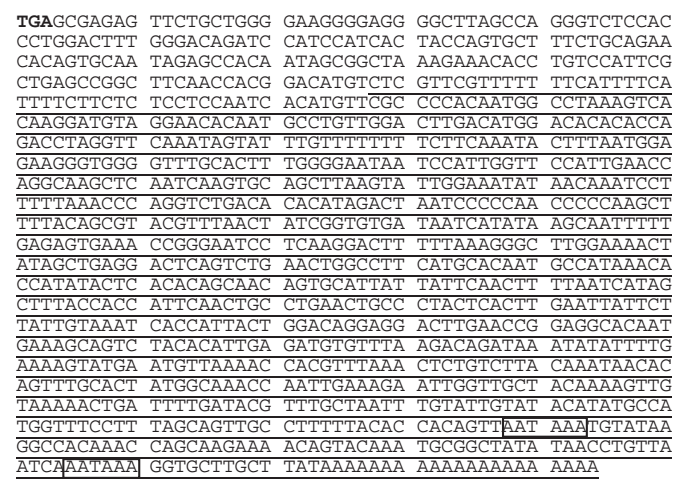

Figure 2 Genomic structure and organization of the $r t M S T N$ - $1 b$ gene. (A) Map of $r t M S T N$ - $1 b$ gene and putative myogenic cisregulatory elements within the promoter region. Exons are boxed with the open reading frame (ORF) in white and untranslated regions (UTR) in gray. Each individual cis element is placed relative to its position within the promoter region and color-coded as indicated in C. Putative E-boxes are numbered. (B) Sequence of the promoter region with color-coded cis elements. Boxed are consensus sequences (CAN(T/A)TG) for E-boxes. Nucleotide position corresponds to the initiator. (C) Key to the colorcoded promoter elements in A and B, and their corresponding positions. (D) Sequence of the $3^{\prime}$ untranslated region. The newly identified sequence is underlined and two potential polyadenylation signal sequences are boxed.

The rtMSTN-1b promoter contained all these putative elements except for the MusIn site and additionally contained a MEF 3 site (Fig. 2). Each promoter also contained an appropriately placed TATA box and several putative E-boxes, while a muscle TATA box was also found in the rtMSTN-1b promoter. A comparative analysis of all cloned myostatin gene promoters from fish revealed features common to all or most promoters and some features unique to a particular promoter as well (Fig. 4). Every promoter contained several E-box motifs and all, but the brook trout (bt) MSTN-1b promoter contained multiple Comp 1 sites and TATA boxes in close proximity to the transcription start sites. Studies with mammalian promoters indicate that MEF2, GRE (glucocorticoid-response element), and MyoD (myogenic differentiation factor) binding sites regulate myostatin promoter transactivation (Ma et al. 2001, Spiller et al. 2002, Forbes et al. 2006). These sites were also identified in the fish promoters. All, but the btMSTN-1b promoter contained multiple MEF2 sites and many were located within the first 500 bp. A GRE was only identified in the btMSTN-1b and zebrafish (zf) MSTN-2 promoters, while the latter additionally contained the only MyoDbinding site as well as two myogenin-binding sites. Roberts \& Goetz (2003) previously identified a MyoD-binding site in the btMSTN-1b promoter, although this site was not identified in our analysis using the same, yet updated software package. 
Rainbow trout MSTN-1a \& $-1 \mathrm{~b}$

\begin{tabular}{|c|c|c|c|c|c|}
\hline M1 & & $\mathrm{P} 125$ & & 2248 & S373 \\
\hline $\mathrm{H}_{2} \mathrm{~N}-$ & MATE & PESI & GEGL & QPFM & $-\mathrm{CO}_{2} \mathrm{H}$ \\
\hline
\end{tabular}

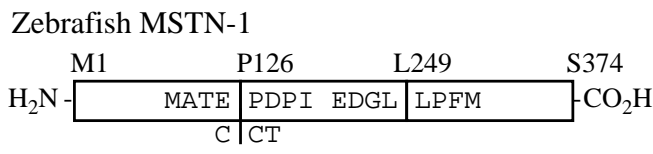

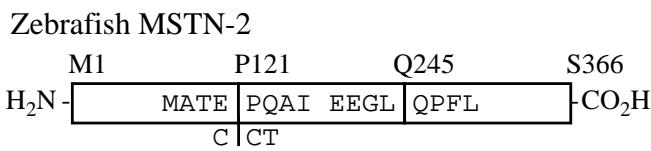

Fugu MSTN-2

\begin{tabular}{|c|c|c|c|c|c|}
\hline M1 & & P109 & & 234 & \\
\hline $\mathrm{H}_{2} \mathrm{~N}-[$ & MATK & PNP I & EEGL & QPFI & \\
\hline
\end{tabular}

\section{Human MSTN}

\begin{tabular}{rr|l|ll}
$\mathrm{M} 1$ & \multicolumn{2}{c}{ D126 } & $\mathrm{N} 250$ & $\mathrm{~S} 376$ \\
$\mathrm{H}_{2} \mathrm{~N}-$ & PTES & DFLM & EDGL & NPFL \\
\hline
\end{tabular}

Figure 3 Comparative mapping of exon boundaries in different myostatin genes. All vertebrate myostatin genes cloned to date are organized into three exons. The three adjoining boxes for each protein represent the coding regions for each exon. Amino acid sequences coded by exon boundaries are shown inside the boxes. The first amino acid coded by each exon is shown above, as is the last residue of the third exons. In all fish genes, the codon of the proline residue located at the first exonic boundary is partially coded by the first and second exon as shown. Locations of the nucleotide splice sites for rtMSTN-1a and $\mathrm{rtMSTN}-1 \mathrm{~b}$ are shown in Figs 1 and 2 and the sequences fit the known consensus.

\section{Embryonic expression}

A quantitative analysis indicated that both rtMSTN-1a and rtMSTN-1b were similarly expressed at low levels during the early stages of development. However, levels of both transcripts rose substantially after eyeing with rtMSTN-1a mRNA levels always greater than those of rtMSTN-1b (Fig. 5A). Expression of both, peaked and dropped immediately before hatching and then continued to rise thereafter. A similar peak in rtMSTN-1a expression also occurred just before yolk sac absorption, although this was not observed with rtMSTN-1b (Fig. 5C). A closer analysis of early developmental stages indicated that neither gene was significantly expressed during gastrulation, although expression of both steadily rose during somitogenesis peaking and then subsided at its end (Fig. 5B).

\section{Adult tissue expression}

Expression of both rtMSTN-1a and rtMSTN-1b was detected in every tissue sampled, including brain, pituitary gland, heart, ovary, testis, kidney, stomach, pyloric ceca, intestine, liver, pancreas, peripheral blood leukocytes, erythrocytes, spleen, gills, branchial arches, fins, skin, eyes, white and red skeletal muscles, and fat (Fig. 6). This includes, some tissues not known to express either myostatin (pituitary, stomach, pyloric ceca, pancreas, leukocytes, erythrocytes, spleen, brachial arches, fins, skin, eyes, and fat) and several others previously thought not to express rtMSTN-1b in particular, which has only been identified in brain and skeletal muscle (Rescan et al. 2001). Expression of both genes was highest (note log scale) in brain, testes, eyes, muscle, and surprisingly spleen. Individual tissue levels of both transcripts were similar in many tissues, but not all. Those of rtMSTN-1a were approximately 50-fold higher than rtMSTN-1b levels in fins and expression of the latter was almost 100-fold greater in leukocytes and gills, and 1000-fold in heart.

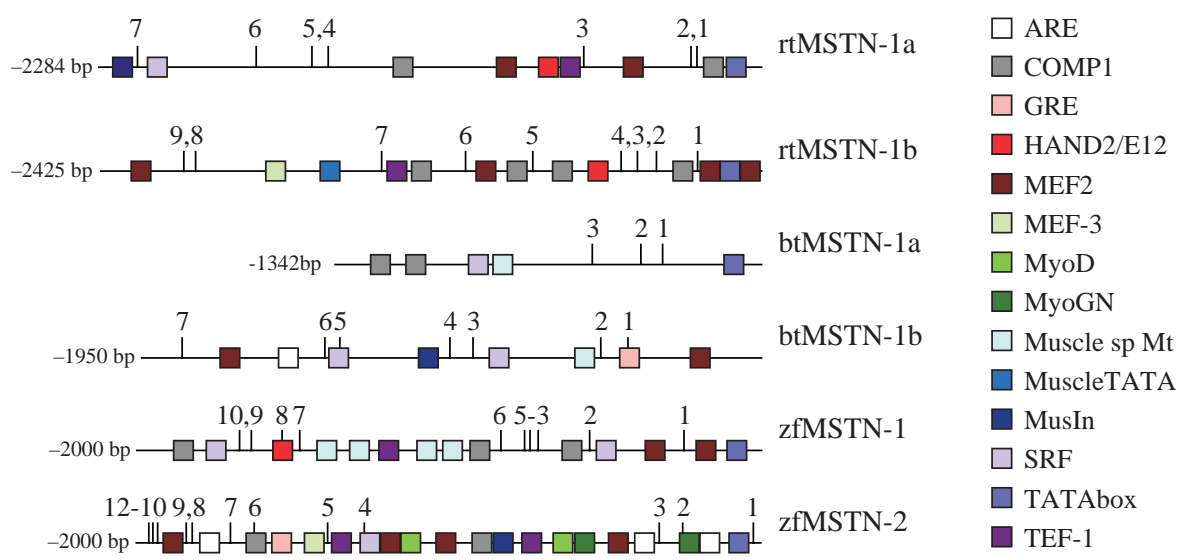

Figure 4 Comparative subsequence analysis of fish myostatin gene promoters. Promoter maps of rainbow trout myostatin rtMSTN-1a and rtMSTN-1b, brook trout btMSTN-1a, and btMSTN-1b and zebrafish zfMSTN-1 and zfMSTN-2 are shown with putative cis-regulatory elements boxed. Putative E-boxes are also indicated and numbered in ascending order starting from the transcription start site on the right. Each element is placed relative to its position within each promoter and is color-coded according to the key. 

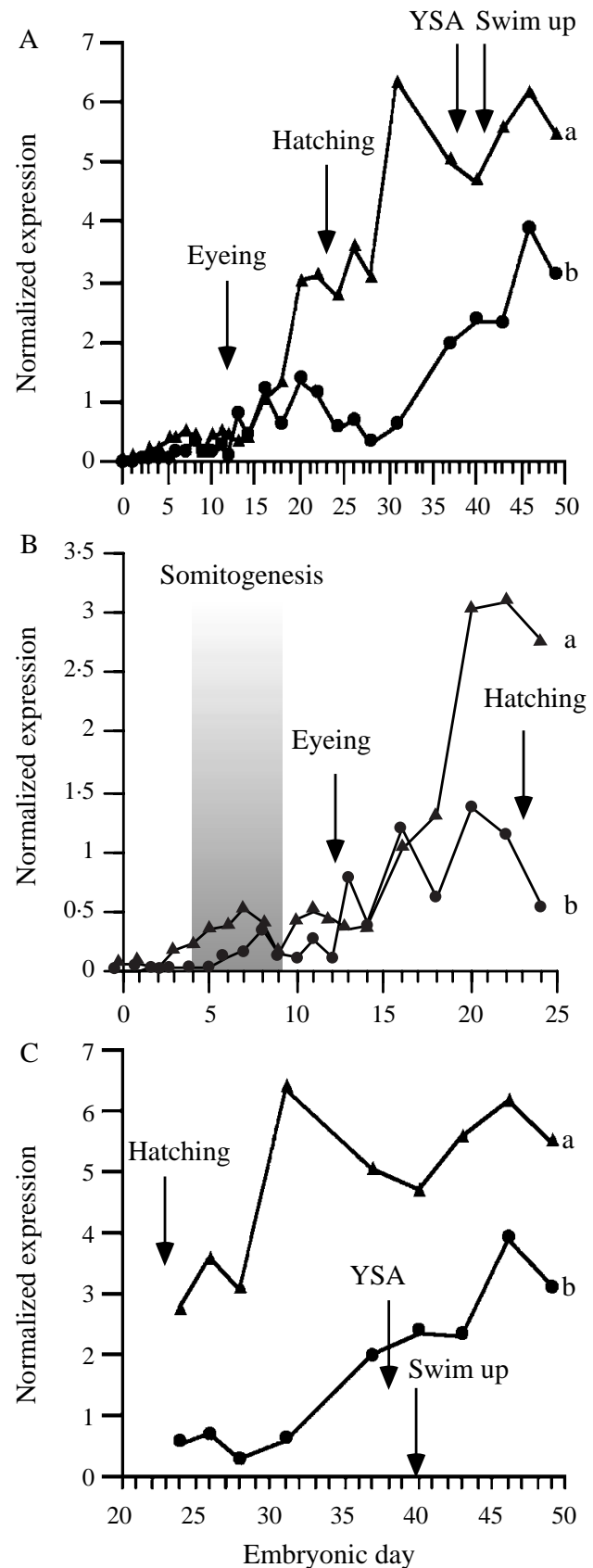

Figure 5 Developmental expression of rtMSTN-1a and rtMSTN-1b. A RNA panel was constructed from 5000 fertilized eggs and developing embryos sampled at the indicated days. Levels of rtMSTN-1a and rtMSTN-1b mRNA were quantified using gene-specific 'real-time' RT-PCR assays. Expression levels throughout the entire period from day 0 (unfertilized) to day 49 are shown in $A$, whereas more detailed assessments of early (days 0-24) and late (days 24-49) stages are shown in (B) and (C) respectively. Key developmental events are indicated by the labeled arrows and the gray box (YSA, yolk sac absorption). Each value represents a mean of three replicate measurements of a single pooled sample ( $n=18$ embryos or 9 posthatched larvae) at each time point. Assay variance was controlled as described in Materials and Methods.

\section{Discussion}

The genomic organization of both the rainbow trout $M S T N-1$ genes (Figs 1 and 2) is highly similar to that of other homologs previously characterized in mammals and nearly identical to those in other fish. Indeed, exon boundaries and pre-mRNA splice sites are even conserved (Fig. 3), especially the second, which separates the coding region of the latency-associated peptide from the bioactive domain of mature myostatin. The amino acid identity of the mature bioactive domains of most fish and mammalian species is $88 \%$ (Rodgers \& Weber 2001), indicating that both primary sequence and gene organization are highly conserved among vertebrates. Although a more comprehensive analysis of genes from divergent fish species and other vertebrate classes is needed to determine the degree of conservation across taxa, these data suggest that strong selective pressures are likely to be responsible and particularly important in preserving fidelity of the third exon. Teleosts commonly possess multiple copies of individual genes. This is a result of an early genome duplication event prior to the teleost radiation, but after the divergence of ray- and lobe-finned fishes (Amores et al. 1998, Postlethwait et al. 1998). A second duplication event specifically within the salmonids (Phillips \& Rab 2001) gave rise to additional ('a' and 'b') myostatin paralogs within each MSTN-1 and MSTN-2 sister clade (Kerr et al. 2005), although none of these genes has been identified to date. Nevertheless, the high degree of genomic and sequence conservation shared among all myostatin genes and fish homologs (Fig. 3) should aid in their isolation and characterization.

Subsequent analysis of the rtMSTN-1a and rtMSTN-1b promoter regions identified several putative cis-regulatory elements that could contribute to the myogenic process. Some of these elements were also identified in the comparable promoters of brook trout (Salvelinus fontinalis) and zebrafish myostatin genes, including multiple MEF2 sites in each (Fig. 4). A putative MyoD site was also identified in the brook trout MSTN-1b promoter by Roberts \& Goetz (2003), although this particular site was not identified in our analysis using the same, yet updated software. Among these fish genes, however, MyoD sites were identified in the zebrafish MSTN-2 promoter, which also contained far more putative myogenic elements than its counterpart (Kerr et al. 2005). Mammalian myostatin promoters contain E-boxes and other elements critical to the differentiation and maturation of skeletal muscle, including both MyoD- and MEF2-binding sites. Indeed, both these sites have been implicated in the regulation of myostatin-gene expression in different animal and cellular systems (Spiller et al. 2002, Salerno et al. 2004, Shyu et al. 2005). Expression of both rtMSTN-1a and $r t M S T N-1 b$ genes increases as somitogenesis progresses and rapidly decreases as it ends (Fig. 5B). This is consistent with increased transactivational activity of these and other myogenicregulatory factors and myostatin's developmental expression 


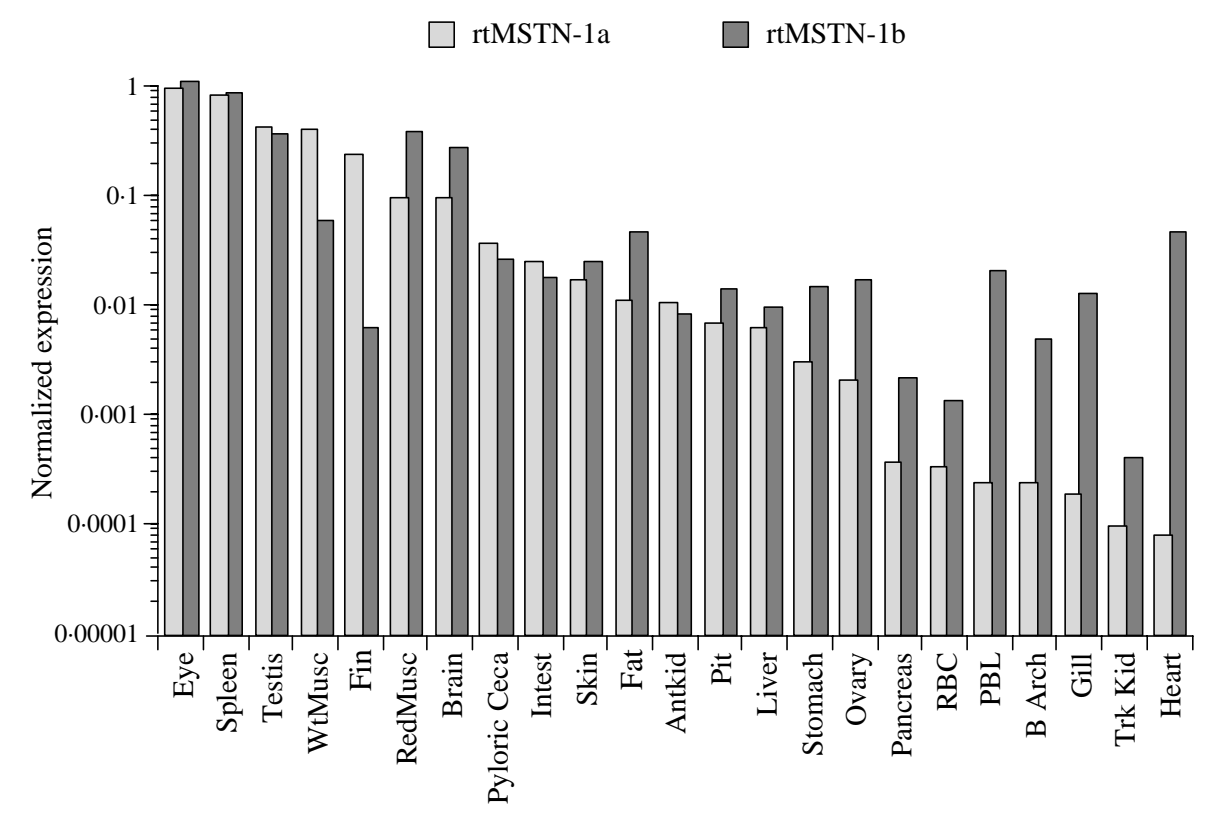

Figure 6 Adult tissue expression of rtMSTN-1a and rtMSTN-1b. Levels of mRNA for both genes were quantified using gene-specific 'real-time' RT-PCR assays and total RNA removed from the indicated tissues. Assays were performed on pooled tissue samples, but were run in triplicate and repeated twice. Mean values are shown. (Pit, pituitary gland; Ant kid, anterior/head kidney; Trk, trunk; Intest, whole intestine; PBL, peripheral blood lymphocytes; RBC, red blood cells; B Arch, branchial arch $w \backslash$ o gill fillaments; Wt Musc, white muscle).

profile in mouse embryos (McPherron et al. 1997). A functional assessment of promoter activity is needed to definitively determine whether these transcription factors regulate either $r t M S T N-1 a$ or $r t M S T N-1 b$ gene expression in developing skeletal muscle. The ubiquitous nature of MSTN-1 expression in fish, however, suggests that additional elements unrelated to myogenesis altogether may be active as well.

Former attempts to define the developmental and tissuespecific expression profiles of fish MSTN-1 genes revealed a far more diverse expression pattern than, which occurs in mammals (Ostbye et al. 2001, Rescan et al. 2001, Rodgers et al. 2001, Maccatrozzo et al. 2001b, Kocabas et al. 2002, Roberts \& Goetz 2003, Rodgers et al. 2003, Vianello et al. 2003, Johansen \& Overturf 2005). These studies were still somewhat limited and mostly qualitative assessments. Rescan et al. reported that rtMSTN-1a mRNA levels were substantially higher than those of rtMSTN-1b in most adult tissues and at the three stages of development (eyeing, hatching, and free-swimming larvae). The one exception was adult brain where expression appeared equal for both genes. This study also indicated a very limited distribution of rtMSTN-1b expression, which was restricted to the brain and the skeletal muscle. By contrast, Ostbye et al. reported a much wider tissue distribution and apparently higher levels, in some tissues, of Atlantic salmon MSTN-1b expression. Both these studies used qualitative RT-PCR assays that do not account for primer efficiency and other aspects of non-quantitative PCR amplification and could have easily underestimated
rtMSTN-1b expression. By contrast, our use of comprehensive RNA panels and a quantitative 'real-time' assay suggest that both $r t M S T N-1 a$ and $r t M S T N-1 b$ genes are expressed much earlier embryologically, specifically during somitogenesis, and in more adult tissues. Expression of both genes was detected in all tissues sampled and surprisingly high in spleen and eyes, which possibly indicates novel functional roles for myostatin in the growth and/or differentiation of immune and proliferative cells of the eye (Reh \& Levine 1998). Johansen and Overturf also analyzed developmental expression of rtMSTN-1a and rtMSTN-1b using a quantitative RT-PCR assay. Although only a few developmental stages were sampled (eyed, hatched/sac present, and swim-up fry), their results also indicate that the expression of both genes rises substantially after eyeing and $\mathrm{rtMSTN}-1 \mathrm{~b}$ mRNA levels are significantly higher than previously reported. Myostatin expression in mammals is first detected within the developing myotome (Kambadur et al. 1997, McPherron \& Lee 1997), although former attempts to localize myostatin message in fish somites have produced mixed results (Xu et al. 2003, Amali et al. 2004, Kerr et al. 2005). Nevertheless, our results are the first to identify a temporal expression pattern in fish that is consistent with a functional role during the early stages of muscle development as levels of both rtMSTN-1a and rtMSTN-1b rise substantially throughout somitogenesis and begin to subside just before this developmental period ends.

The expression patterns described and the subsequence analysis of the different promoters further support a role for 
both the MSTN-1 genes during fish myogenesis, although the ubiquitous expression pattern in different adult tissues suggests that the functional role of cytokine is far more diverse than that in mammals. The presence of multiple fish genes that are differentially expressed throughout development and adult tissues also suggests that the precise role of a particular gene may vary between tissues. A better understanding of physiological factors that influence the expression of each gene and the transcriptional machinery involved will, therefore, help distinguish the potential divergent actions of myostatin in fish and mammals.

\section{Acknowledgements}

This work was supported by a grant from the United States Department of Agriculture (2004-34468-15199) to Buel D Rodgers. The authors wish to acknowledge Dr Carid Rexroad III, Kristy Anderson and Roseanna Athey for the assistance with embryonic sampling and tissue collection. The authors declare that there is no conflict of interest that would prejudice the impartiality of this scientific work.

\section{References}

Amali AA, Lin CJ, Chen YH, Wang WL, Gong HY, Lee CY, Ko YL, Lu JK, Her GM, Chen TT et al. 2004 Up-regulation of muscle-specific transcription factors during embryonic somitogenesis of zebrafish (Danio rerio) by knock-down of myostatin-1. Developmental Dynamics 229 847-856.

Amores A, Force A, Yan YL, Joly L, Amemiya C, Fritz A, Ho RK, Langeland J, Prince V, Wang YL et al. 1998 Zebrafish hox clusters and vertebrate genome evolution. Science 282 1711-1714.

Forbes D, Jackman M, Bishop A, Thomas M, Kambadur R \& Sharma M 2006 Myostatin auto-regulates its expression by feedback loop through Smad7 dependent mechanism. Journal of Cellular Physiology 206 264-272.

Gonzalez-Cadavid NF, Taylor WE, Yarasheski K, Sinha-Hikim I, Ma K, Ezzat S, Shen R, Lalani R, Asa S, Mamita M et al. 1998 Organization of the human myostatin gene and expression in healthy men and HIV-infected men with muscle wasting. PNAS 95 14938-14943.

Jeanplong F, Sharma M, Somers WG, Bass JJ \& Kambadur R 2001 Genomic organization and neonatal expression of the bovine myostatin gene. Molecular and Cellular Biochemistry 220 31-37.

Johansen KA \& Overturf K 2005 Quantitative expression analysis of genes affecting muscle growth during development of rainbow trout (Oncorhynchus mykiss). Marine Biotechnology 7 576-587.

Kambadur R, Sharma M, Smith TP \& Bass JJ 1997 Mutations in myostatin (GDF8) in double-muscled Belgian Blue and Piedmontese cattle. Genome Research 7 910-916.

Kerr T, Roalson EH \& Rodgers BD 2005 Phylogenetic analysis of the myostatin gene sub-family and the differential expression of a novel member in zebrafish. Evolution and Development 7 390-400.

Kocabas AM, Kucuktas H, Dunham RA \& Liu Z 2002 Molecular characterization and differential expression of the myostatin gene in channel catfish (Ictalurus punctatus). Biochimica et Biophysica Acta 1575 99-107.

Langley B, Thomas M, Bishop A, Sharma M, Gilmour S \& Kambadur R 2002 Myostatin inhibits myoblast differentiation by down regulating MyoD expression. Journal of Biological Chemistry 1818.

Langley B, Thomas M, McFarlane C, Gilmour S, Sharma M \& Kambadur R 2004 Myostatin inhibits rhabdomyosarcoma cell proliferation through an Rb-independent pathway. Oncogene 23 524-534.

Lee SJ 2004 Regulation of muscle mass by myostatin. Annual Review of Cell and Developmental Biology 20 61-86.
Ma K, Mallidis C, Artaza J, Taylor W, Gonzalez-Cadavid N \& Bhasin S 2001 Characterization of $5^{\prime}$-regulatory region of human myostatin gene: regulation by dexamethasone in vitro. American Journal of PhysiologyEndocrinology and Metabolism 281 E1128-E1136.

Maccatrozzo L, Bargelloni L, Cardazzo B, Rizzo G \& Patarnello T 2001a A novel second myostatin gene is present in teleost fish. FEBS Letters 509 36-40.

Maccatrozzo L, Bargelloni L, Radaelli G, Mascarello F \& Patarnello T $2001 b$ Characterization of the myostatin gene in the gilthead seabream (Sparus aurata): sequence, genomic structure, and expression pattern. Marine Biotechnology 3 224-230.

McCroskery S, Thomas M, Maxwell L, Sharma M \& Kambadur R 2003 Myostatin negatively regulates satellite cell activation and self-renewal. Journal of Cell Biology 162 1135-1147.

McPherron AC \& Lee SJ 1997 Double muscling in cattle due to mutations in the myostatin gene. PNAS 94 12457-12461.

McPherron AC, Lawler AM \& Lee SJ 1997 Regulation of skeletal muscle mass in mice by a new TGF-beta superfamily member. Nature 387 83-90.

Ostbye TK, Galloway TF, Nielsen C, Gabestad I, Bardal T \& Andersen O 2001 The two myostatin genes of Atlantic salmon (Salmo salar) are expressed in a variety of tissues. European Journal of Biochemistry 268 5249-5257.

Phillips R \& Rab P 2001 Chromosome evolution in the Salmonidae (Pisces): an update. Biological Reviews of the Cambridge Philosophical Society 76 1-25.

Postlethwait JH, Yan YL, Gates MA, Horne S, Amores A, Brownlie A, Donovan A, Egan ES, Force A, Gong Z et al. 1998 Vertebrate genome evolution and the zebrafish gene map. Nature Genetics 18 345-349.

Reh TA \& Levine EM 1998 Multipotential stem cells and progenitors in the vertebrate retina. Journal of Neurobiology 36 206-220.

Rescan PY, Jutel I \& Ralliere C 2001 Two myostatin genes are differentially expressed in myotomal muscles of the trout (Oncorhynchus mykiss). Journal of Experimental Biology 204 3523-3529.

Rios R, Carneiro I, Arce VM \& Devesa J 2001 Myostatin regulates cell survival during $\mathrm{C} 2 \mathrm{C} 12$ myogenesis. Biochemical and Biophysical Research Communications 280 561-566.

Rios R, Carneiro I, Arce VM \& Devesa J 2002 Myostatin is an inhibitor of myogenic differentiation. American Journal of Physiology - Cell Physiology 282 C $993-$ C 999.

Roberts SB \& Goetz FW 2001 Differential skeletal muscle expression of myostatin across teleost species, and the isolation of multiple myostatin isoforms. FEBS Letters 491 212-216.

Roberts SB \& Goetz FW 2003 Myostatin protein and RNA transcript levels in adult and developing brook trout. Molecular and Cellular Endocrinology 210 9-20.

Rodgers BD \& Weber GM 2001 Sequence conservation among fish myostatin orthologues and the characterization of two additional cDNA clones from Morone saxatilis and Morone americana. Comparative Biochemistry and Physiology. Part B, Biochemistry and Molecular Biology 129 597-603.

Rodgers BD, Weber GM, Sullivan CV \& Levine MA 2001 Isolation and characterization of myostatin complementary deoxyribonucleic acid clones from two commercially important fish: Oreochromis mossambicus and Morone chrysops. Endocrinology 142 1412-1418.

Rodgers BD, Weber GM, Kelley KM \& Levine MA 2003 Prolonged fasting and cortisol reduce myostatin mRNA levels in tilapia larvae; short-term fasting elevates. American Journal of Physiology - Regulatory, Integrative and Comparative Physiology 284 R1277-R1286.

Salerno MS, Thomas M, Forbes D, Watson T, Kambadur R \& Sharma M 2004 Molecular analysis of fiber-type specific expression of murine myostatin promoter. American Journal of Physiology - Cell Physiology 287 C1031-C1040. Schuelke M, Wagner KR, Stolz LE, Hubner C, Riebel T, Komen W, Braun T, Tobin JF \& Lee SJ 2004 Myostatin mutation associated with gross muscle hypertrophy in a child. New England Journal of Medicine 350 2682-2688.

Shyu KG, Ko WH, Yang WS, Wang BW \& Kuan P 2005 Insulin-like growth factor-1 mediates stretch-induced upregulation of myostatin expression in neonatal rat cardiomyocytes. Cardiovascular Research 68 405-414.

Spiller MP, Kambadur R, Jeanplong F, Thomas M, Martyn JK, Bass JJ \& Sharma M 2002 The myostatin gene is a downstream target gene of basic helix-loop-helix transcription factor MyoD. Molecular and Cellular Biology 22 7066-7082. 
Stratil A \& Kopecny M 1999 Genomic organization, sequence and polymorphism of the porcine myostatin (GDF8; MSTN) gene. Animal Genetics 30 468-470.

Thomas M, Langley B, Berry C, Sharma M, Kirk S, Bass J \& Kambadur R 2000 Myostatin, a negative regulator of muscle growth, functions by inhibiting myoblast proliferation. Journal of Biolgical Chemistry 275 40235-40243.

Vianello S, Brazzoduro L, Dalla Valle L, Belvedere P \& Colombo L 2003 Myostatin expression during development and chronic stress in zebrafish (Danio rerio). Journal of Endocrinology 176 47-59.
Xu C, Wu G, Zohar Y \& Du SJ 2003 Analysis of myostatin gene structure, expression and function in zebrafish. Journal of Experimental Biology 206 4067-4079

Received 15 March 2006

Received in final form 9 June 2006

Accepted 21 June 2006

Made available online as an Accepted Preprint 30 June 2006 